\title{
DESAIN ARTWORK PADA TAMAN PULAU DAN MEDIAN JALAN DI JALAN MEDAN MERDEKA JAKARTA
}

\section{Artwork Design on The Traffic \\ Island and Street Median in \\ Medan Merdeka Street, Jakarta}

Sigit Mulyansyah Effendy

Alumni Departemen Arsitektur Lanskap

Fakultas Pertanian IPB

e-mail: s_mulyansyah@yahoo.com

Dewi Rezalini Anwar

Staf Pengajar Departemen Arsitektur Lanskap IPB

\begin{abstract}
Open space is a part of the community's needs for leisure. Open space can have many forms and functions. One of them is the traffic island and street median. Traffic Island and street median has potential as a media of display to form character and give a mental map for an area. Character of a region can be shaped with elements inside, one of these with the placement of the artwork. Artwork can be a an element mental map to guide a person to move from one point to other, especially in big cities such as Jakarta. The Medan Merdeka road is surrounded by traffic islands, up to now still not have character and appeal to form a mental map of its users. This study aims to create the artwork design can shape the character and attitudes docket in the Medan Merdeka Area. This activity is carried out on the grounds of The Medan Merdeka region in 16 weeks with the method of direct observation and interviews. The Output from this research includes the design artwork on the traffic Island to has function as a mental map in the area.
\end{abstract}

Key words: Artwork, mental map, open space, street median, traffic island

\section{PENDAHULUAN}

Ruang terbuka merupakan bagian yang dapat dimanfaatkan secara langsung oleh masyarakat, dapat berbentuk area/kawasan atau area memanjang/jalur. Taman pulau dan median jalan merupakan salah satu bentuk pemanfaatan dari ruang terbuka. Dalam merancang taman pulau dan median jalan perlu diperhatikan elemen-elemen pembentuknya agar dapat memberikan karakter pada jalan. Taman pulau dan median jalan juga memiliki potensi untuk dijadikan media untuk menampilkan artwork yang menarik sebagai identitas kawasan dan elemen mental map bagi penggunanya (Porteous, 1977).

Artwork adalah salah satu bagian dari elemen lanskap, pembentuk karakter dari ruang publik/identitas kawasan. Karakter tapak yang menarik harus dipertahankan atau diciptakan, sehingga semua elemen lanskap yang banyak variasinya dapat menjadi satu kesatuan yang harmonis (Simonds dan Starke 2006). Pentingnya suatu artwork dapat menjadi landmark dan dapat memberi daya tarik secara visual. Menurut Porteus (1977) suatu landmark harus memiliki legibility/sense of place, dengan memperhatikan atribut bentuk, atribut visibilitas, dan atribut dari makna dan penggunaan suatu artwork maka diperlukan desain yang dapat memenuhi fungsi tersebut.

Jalan Medan Merdeka yang merupakan kawasan dari pusat pemerintahan dan area perkantoran. Taman pulau dan median jalannya masih belum memiliki daya tarik dan karakter yang kuat untuk membentuk mental map bagi penggunanya. Untuk memberikan daya tarik tersebut maka diperlukan studi desain artwork pada taman pulau dan median jalan di Jalan Medan Merdeka. Tujuan dari studi ini ialah 1) mengidentifikasi dan menganalisis kebutuhan user akan artwok dan aspek-aspek pembentuk artwork pada taman pulau dan median jalan di Jalan. Medan Merdeka sebagai pembentuk indentitas kawasan untuk pembentuk mental map; 2) membuat konsep artwork pada taman pulau dan median jalan di Jalan Medan Merdeka; 3) membuat desain dari artwork yang memiliki nilai fungsional dan estetika juga dapat diaplikasikan pada taman pulau dan median jalan di Jalan Medan Merdeka. Manfaat dari penelitian ini ialah 1) menambah karya baru di bidang arsitektur lanskap; 2) dapat menjadi referensi bagi pihak-pihak terkait dalam merancang/desain artwork; 3) menjadi referesi perancangan taman pulau yang lebih menarik; 4) menambah fungsi ruang terbuka.

\section{METODE PENELITIAN}

\section{Lokasi dan Waktu Penelitian}

Penelitian ini dilaksanakan di taman pulau dan median jalan yang berlokasi di Jalan Merdeka Utara, Timur, Selatan dan Barat, Provinsi DKI Jakarta. Penelitian ini dilakukan mulai Januari hingga Mei 2013.

\section{MetodePenelitian}

Metode yang digunakan selama kegiatan penelitian desain artwork pada taman pulau dan median jalan ini adalah sebagai berikut.

\section{Identifikasi}

1.1. Observasi atau pengamatan secara langsung terhadap tapak pada pagi hari hingga siang hari dan sore hari hingga malam hari. Kegiatan ini bertujuan untuk mendapatkan data fisik dan biofisik seperti bentukanbentukan elemen lanskap dan intensitas cahaya matahari pada bagian tertentu di dalam tapak yang akan mempengaruhi bentukan artwork yang akan didesain.

1.2. Wawancara dalam bentuk kuesioner tertutup (purposive sampling) dengan pengguna tapak yang dipilih secara sengaja sebanyak 30 responden yang disebar ke dalam 
empat lokasi untuk mengetahui persepsi masyarakat mengenai pentingnya suatu artwork, dan wawancara dalam bentuk kuisoner terbuka (indepth interview) ditunjukan kepada (2 responden) pengelola/DKP DKI Jakarta, (2 responden) seniman, (1 responden) arsitek lanskap dan (1 responden) tenaga ahli. untuk mendapatkan persepsi dan sudut pandang mengenai desain artwork yang menjadi pertimbangan dalam mendesain.

\section{Analisis dan Sintesis}

Analisis dan sintesis dilakukan dengan pendekatan aspek sebagai berikut.

\subsection{Aspek Seni dan Sosial}

Pendekatan ini dilakukan untuk mendapatkan desain artwork yang memiliki nilai estetik dan fungsional dengan melakukan analisis secara spasial dan deskriptif.

\subsection{Aspek Pengguna}

2.2.1. Pendekatan psikologis: pendekatan ini dilakukan untuk mengetahui fungsi artwork nantinya terhadap emosional user/pengguna untuk membentuk elemen mental map seperti memperhatikan jarak pandang, dan dimensi artwork.

2.2.2. Pendekatan keamanan dan kenyamanan: pendekatan ini dilakukan untuk mempertimbangkan arah dan arus sirkulasi dalam menentukan titik peletakan artwork untuk memberikan keamanan dan kenyamanan bagi pengguna jalan. Menurut Harris dan Dines (1998) maka perlu memperhatikan jarak pandang pengguna terhadap objek didepannya. Untuk menghitung jarak pandang antara pengguna dan artwork maka diketahui rumus berikut.

Persepsi dan reaksi (Pr):

$$
\operatorname{Pr}=1.47(\mathrm{t})(\mathrm{v})
$$$$
\operatorname{Pr}=\text { Untuk }
$$

menghitung jarak ketika pengemudi bereaksi dan member persepsi terhadap objek didepannya (m). t = Waktu yang dibutuhkan ketika bereaksi dan member persepsi terhadap objek (2.5 Detik).

$\mathrm{v}=$ Kecepatan kendaraan (Jalan Medan Merdeka termasuk jalan protokol dengan kecepatan rat-rata $40 \mathrm{~km} / \mathrm{jam})$.

Jarak berhenti $(\mathrm{d})$ :

$$
\mathrm{D}={\frac{V^{2}}{30 f}}^{2}
$$

$\mathrm{d}=$ Jarak untuk menginterpretasi objek (m).

$\mathrm{v}=$ Kecepatan kendaraan (Jalan Medan Merdeka termasuk jalan protokol dengan kecepatan rat-rata $40 \mathrm{Km} / \mathrm{Jam}$ ).

$\mathrm{f}=$ Nilai koefisien (dipengaruhi lelah dan jenis perkerasan $)(0,60)$.

Jarak pandang minimum (D):

$$
\mathrm{D}=\mathrm{Pr}+\mathrm{d}
$$

Penelitian ini merupakan kegiatan proses desain artwork pada taman pulau dan median jalan di kawasan Jalan Medan Merdeka Jakarta, dengan memperhatikan atributatribut penting untuk membentuk karakter suatu kawasan agar dapat menjadi elemen mental map. Atributatribut tersebut dipelajari melalui masyarakat yang berpotensi sebagai pengguna. Proses desain yang digunakan dalam penelitian ini mengikuti teori Simonds 1996 meliputi commissioning, inventarisasi, analisis, sintesis, konsep desain, konstrusi, dan pelaksanaan.

\section{Batasan Penelitian}

Batasan pada penelitian ini yaitu untuk mengetahui pentingnya suatu artwork bagi pengguna dan elemenelemen pembentuk artwork di kawasan Jalan Medan Merdeka Jakarta. Desain artwork dan gambar kerja berupa gambar detil, potongan dan perspektif.

\section{HASIL DAN PEMBAHASAN}

\section{Kondisi Umum}

Aspek Fisik dan Biofisik
Lokasi pulau jalan(Traffic Island) dan median jalan ini berada di daerah Jakarta pusat tepatnya berada di Jalan Medan Merdeka Utara, Selatan, Barat dan Timur berbatasan dengan wilayah pusat perkantoran dan pusat pemerintahan nasional.

Menurut Indra Riyanto (2009), wilayah DKI Jakarta terbagi atas tiga tingkat ketinggian yang dominan. Jakarta pusat termasuk dalam kategori dengan ketinggian permukaan tanah kurang dari 10 mdpl dan termasuk dalam kategori topografi relatif datar dengan nilai kemiringan $0-8 \%$ dan berada pada dataran rendah.

Kondisi drainase tapak cukup baik, air dalam tapak mengarah ke aliran drainase terdekat, namun jika curah hujan tinggi drainase tapak akan menggenang bahkan banjir akibat penutup/pemlesteran dengan beton dan kurangnya resapan air kedalam tanah. Jenis tanah pembentuk di Jakarta Pusat termasuk jenis tanah alluvial atau disebut dengan inseptisol dengan tingkat kesuburan yang tinggi (Ballittanah 2013), namun tnah pada bagian median biasanya merupakan tanah urug yang sumbernya bukan tanah asli setempat.

Pada umumnya struktur dan vegetasi yang digunakan pada jalan merupakan vegetasi yang berfungsi untuk mengarahkan dan vegetasi estetika untuk membentuk karakter jalan. Fungsi utama vegetasi diperkotaan untuk menanggulangi penurunan kualitas lingkungan dan berkaitan langsung dengan kehidupan penghuni kota serta sebagai satu kesatuan sistem ekologi kota Wungkar (2005).

Jalan Medan Merdeka dapat diakses melalui Jalan M.H Thamrin, Jalan Majapahit, Jalan Veteran, Jalan Perwira, Jalan Pejambon, dan Jalan Moch Ichwan Ridwan Rais. Kondisi sirkulasi cukup lancar dan kondisi jalan yang baik. median jalannya memiliki ukuran yang berbeda sehingga mempengaruhi akses kedalam median jalan tersebut. Sirkulasi primer termasuk dalam kategori jalan protokol atau disebut juga sebagai jalan kolektor. Masingmasing visual pada tapak memiliki karekter yang berbeda-beda. Visual 
pada tapak yang baik berada pada Medan merdeka barat dan selatan karena memiliki sudut dan jarak pandang yang lebih luas dan mengarah ke patung Arjuna Wijaya dan patung Thamrin.

Elemen seni pada tapak ialah patung Arjuna Wijaya, Patung Thamrin, dan Gerombong (gambar 6) . Kondisi elemen seni cukup baik karena diletakkan pada posisi yang strategis sehingga memiliki visual yang baik. Fungsi dari elemen seni tersebut sebagai elemen estetika kota untuk menambah keindahan dan memanfaatkan median dan taman pulau sebagai media display. Keberadaan elemen seni di tapak belum dapat menjadi landmark bagi kawasan setempat.

\section{Aspek Sosial}

\section{Pengguna}

Pengunaan tapak cukup padat pada pukul 08.00-10.00 dan 16.00-17.00 dikarenakan waktu masuk bekerja dan waktu pulang bekerja. Penguna tapak didominasi oleh pekerja kantor yang berada pada kawasan tersebut Selain pengguna didalam tapak, ada juga pengguna diluar tapak seperti pengguna dengan kendaraan bermotor yang memanfaatkan tapak sebagai area berputar arah, pembatas jalan, dan keamanan.

\section{Pengelola}

Tapak dikelola oleh Dinas Pemakaman dan Pertamanan DKI Jakarta di bagian tata hijau dan keindahan kota. Fungsi dari artwork diharapkan tidak hanya menjadi elemen estetis tetapi juga dapat menjadi fungsi mental map bagi penggunanya. Selain itu elemen tersebut juga memperhatikan keselamatan bagi pengguna jalan. Pengelola juga mengharapkan penggunaan material yang ramah lingkungan, tahan lama, dan pengelolaan yang minimum.

\section{Aspek Seni}

\section{Prinsip Artwork}

Aspek-aspek yang perlu diperhatikan yang dapat meningkatkan sense of place suatu artwork dengan memperbaiki legibilitasnya untuk memberikan karakter pada suatu ruang (Porteous 1977), yaitu struktur (form), visual, kegunaan dan simbolis.

2. Artwork sebagai Elemen
Lanskap

Artwork sebagai bagian dari elemen pembentuk lanskap maka perlu memperhatikan lingkungan sekitarnya Ketut Winata (2013), karena artwork dapat memberikan pengertian/makna terhadap ruang dalam bentuk simbolik . selain itu artwork juga perlu memiliki nilai yang harmonis terhadap fisik lingkungannya. Untuk itu maka perlu memperhatikan aspek-aspek yang dapat membentuk monumentalitas sebuah artwork terhadap lingkungannya.

\section{Monumentalitas artwork}

Arie Bastaman (2013) mengatakan bahwa untuk menciptakan karya seni (arsitektural) yang monumental perlu memperhatikan jarak pandang, dimensi lingkungan, struktur, apakah keberadaan karya seni dapat menambah kekuatan kawasan atau tidak, bentuk, siluet. Selain fungsi sosial fungsi sebuah karya seni (arsitektur) juga dapat meningkatkan kualitas lingkungan, meningkatkan karakter kawasan, menjadi elemen mental map, dan memberi citra kawasan. Selain dimensi terhadap ruang material juga dapat memberikan dan menciptakan kesan monumentalitas terhadap artwork.

\section{Material Artwork}

Material ruang luar sangat peka terhadap perubahan iklim. Pemilihan material yang tepat juga dapat memberikan karakter terhadap artwork. Karakter material dapat memperkuat konsep estetika menurut Arie bastaman. Menurut Tatang Ramadhan pemilihan material ruang luar perlu memperhatikan cuaca, material yang baik adalah material yang adaptif terhadap perubahan cuaca, tahan lama dan kontemporer, jenis dan material ruang luar sudah banyak dan dapat diaplikasikan seperti perunggu, tembaga, kuningan, alumunium, granit, kaca. material juga dapat menggunakan tanaman untuk membentuk artwork. Karakter artwork juga dapat diciptakan menggunakan material yang memiliki tekstur atau memberikan warna pada artwork.

\section{Artwork Medan Merdeka}

$\begin{array}{lrr}\begin{array}{l}\text { Menurut Tatang } \\ \text { peletakan artwork }\end{array} & \begin{array}{r}\text { Ramadhan } \\ \text { menjadi } \\ \text { dengan }\end{array} \\ \text { memperhatikan tingkat } & \text { sosial }\end{array}$ masyarakat pada suatu kawasan untuk menentukan simbol yang dihadirkan dalam bentuk artwork. Jakarta sebagai ibu kota negara memiliki dua wajah, apakah sebagai wajah budaya lokal atau wajah internasional yang menentukan peradaban suatu bangsa.

\section{ANALISIS DAN SINTESIS}

\section{Kondisi Fisik dan Biofisik}

\section{Lokasi dan Batas Tapak}

Medan merdeka sebagai ring satu seharusnya menampilkan artwork kontemporer modern sebagai bentuk peradaban seni suatu bangsa menurut Tatang Ramadhan. Menurut Ketut Winata manusia cenderung ingin mudah dan simple dalam mengingat dan memperhatikan bentuk khususnya artwork pada area publik.

\section{Topografi}

Menurut Booth (1983), tapak yang memiliki topografi dengan kategori datar merupakan tapak ideal dan dapat dikembangkan secara maksimal. Maka tapak datar pada tapak berpotensi untuk ditambahkan artwork vertikal untuk memberikan vocal point pada tapak.

\section{Aksesibilitas dan Sirkulasi}

Berdasarkan perhitungan, jarak pandang yang aman bagi pengendara bermotor terhadap artwork (gambar 7) adalah:

Persepsi dan reaksi (Pr):

$$
\begin{aligned}
\operatorname{Pr} & =1.47(2.5)(40) \\
& =44.1 \mathrm{~m}
\end{aligned}
$$

Jarak Berhenti (d):

$\mathrm{d} \quad==2670 \mathrm{~cm}=26.7 \mathrm{~m}$

Jarak pandang minimum (D):

$\mathrm{D} \quad=4410+2670=70.8 \mathrm{~m}$ 
Jarak yang masih dapat diterima seseorang ketika berjalan kaki ialah 24 meter dengan kecepatan rata-rata orang dewasa berjalan normal menurut Harris dan Dines (1998) ialah $4.3 \mathrm{~km} / \mathrm{jam}$ agar dapat menginterpretasi artwork.

\section{Visual}

Visibilitas pengguna jalan perlu diperhatikan untuk memberikan interpretasi dan keamanan bagi pengguna jalan.Sudut pandang horizontal pengguna jalan yang menggunakan kendaraan bermotor dan pejalan kaki memiliki lebar sudut yang sama yaitu 60. Sudut pandang vertikal pejalan kaki dan pengguna kendaraan bermotor memiliki sudut pandang yang berbeda. Sudut pandang pengendara bermotor ialah $12^{\circ}$ sedangkan pejalan kaki adalah $30^{\circ}$.
Sudut pandang vertikal digunakan untuk membaca objek secara spasial. Tinggi maksimum artwork agar dapat menjadi vocal point dengan perbandingan antara jarak dan tinggi artwork yaitu 4:1. Dengan perbandingan tersebut artwork dapat menjadi terlihat monumentalitas terhadap lingkungannya. Dengan perhitungan yang telah diketahui bahwa jarak rata-rata pengendara bermotor dan pejalan kaki sebesar $47.4 \mathrm{~m}$ maka :

$$
\begin{array}{ll}
\text { 4h } & =47.4 \\
\mathrm{H} & =11.85 \mathrm{~m}
\end{array}
$$

Rata-rata lebar median dan taman pulau sebesar $10.38 \mathrm{~m}$

Maka panjang dan lebar dari artwork adalah $11.85 \mathrm{~m} / 10.38 \mathrm{~m}=1.38 \mathrm{~m}$

Potensi visual pengguna tapak diarahkan ke artwork. Untuk menghasilkan visual yang maksimal perlu memperhatikan jarak pandang pengguna kendaraan bermotor dan

\section{Gambar 1. Analisis Sirkulasi}

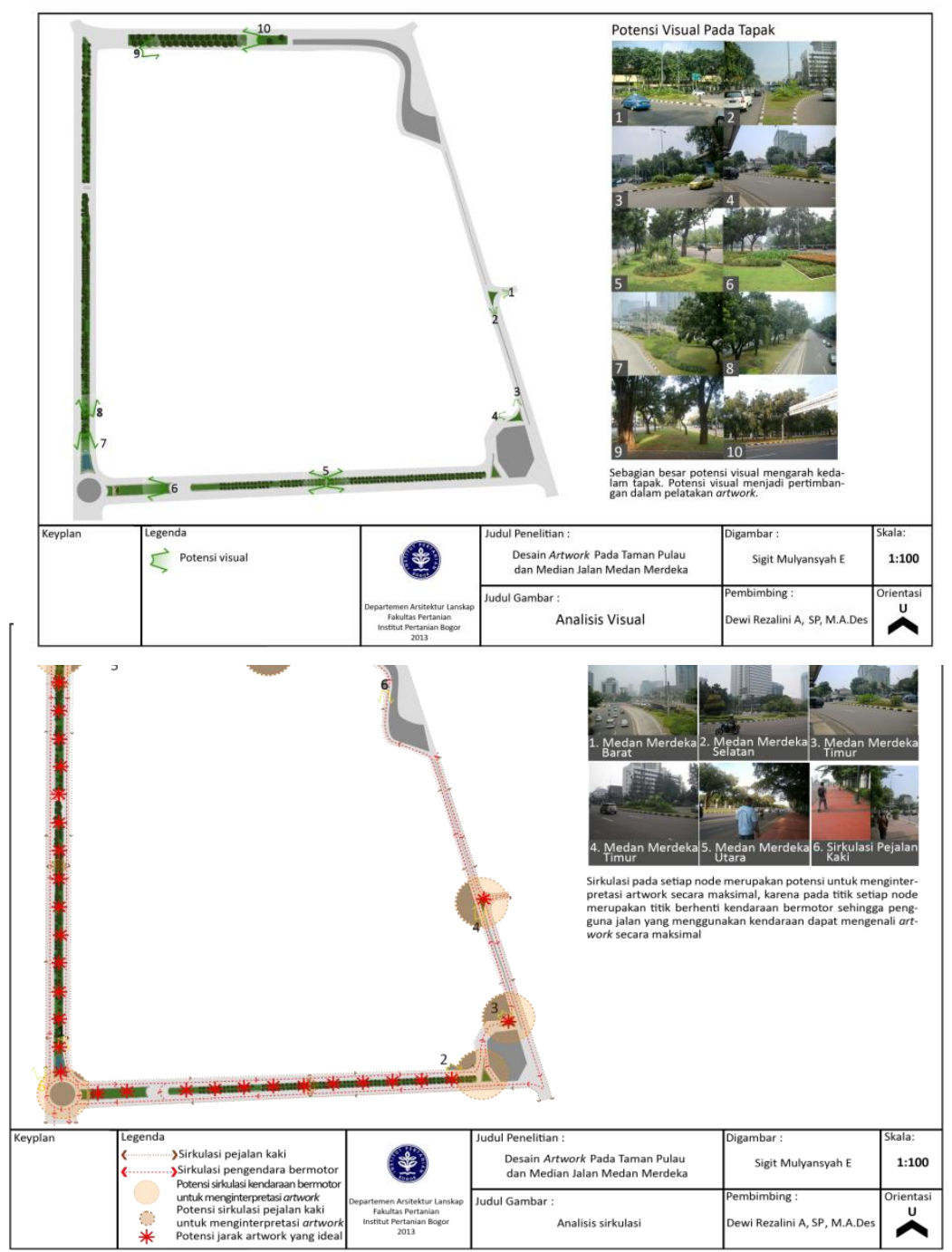

pejalan kaki. Sudut pandang pengguna dipertimbangkan untuk mengetahui dimensi artwork terhadap ruang (Gambar 2).

\section{Vegetasi}

Vegetasi merupakan elemen yang penting untuk memperkuat karakter suatu lanskap. Menurut Booth (1983) batang dan cabang perdu dapat menjadi latar (foreground) terhadap satu ruang yang menjadi vocal point. Semak yang tinggi dapat berfungsi sebagai latar (background) yang netral pada objek yang ada didepannya.

\section{Aspek Sosial}

Aspek sosial yang dianalisis berdasarkan hasil kuisioner yang diberikan pada responden yang dipilih secara sengaja pada kawasan Jalan Medan Merdeka. Untuk mengetahui aspek sosial yang dapat mempengaruhi desain artwork diklasifikasin yaitu sebagai berikut.

Fungsi Artwork sebagai Elemen Mental Map

Responden menyatakan bahwa mereka masih sulit mengenali perbedaan lokasi antara Medan Merdeka Utara, Barat, Selatan dan Timur sehingga mereka sering mengalami disorientasi, diketahui bahwa $80 \%$ dari hasil responden mengenali masing-masing lokasi hanya dari bangunan yang sudah menjadi landmark bagi setiap lokasinya.

\section{Elemen Artwork sebagai Fungsi Aktif}

Responden menyatakan artwork perlu berfungsi sebagai elemen taman seperti bangku taman, lampu, air mancur dan sebagainya sehingga memiliki fungsi aktif. Fungsi aktif juga dapat memudahkan masyarakat mengenali artwork dan menjadi elemen yang dapat digunakan sehingga tidak hanya menjadi elemen yang pasif yang hanya dapat dilihat.

Porteous (1977) menyatakan bahwa perlu memperhatikan struktur untuk membentuk mental map. Bentuk/pola artwork menjadi struktur untuk memperkuat karakter dan memberi pembeda bagi masing masing lokasi. Responden 
menyatakan mereka menginginkan bentuk kombinasi dari organic dan geometrik.

\section{Aspek Seni}

Dalam menciptakan artwork perlu memperhatikan aspek-aspek pembentuknya. Menurut Porteous (1977) aspek-aspek tersebut akan memberikan karakter yang kuat dan memperbaiki legibilitasnya terhadap lingkungannya sehingga dapat menjadikan artwork sebagai elemen mental Map.

\section{Konsep}

\section{Konsep Dasar}

Konsep dasar mengangkat filosofi berdasarkan sejarah kepemimpinan karena lokasi berada pada area pemerintahan. Menurut Taufik Kiemas, nilai-nilai kepemimpinan sudah mulai luntur karena degradasi moral secara signifikan. Dalam keprihatinan tersebut maka Taufik Kiemas mengagaskan mengenai empat pilar kebangsaan. Empat pilar kebangsaan menurut Taufiq Kiemas. Empat pilar tersebut yaitu Negara Kesatuan Republik Indonesia (NKRI), Pancasila, UUD, dan Bhinneka Tunggal Ika. Empat pilar tersebut perlu dipahami dan dipraktikan sebagai kearifan bangsa.

\section{Konsep Desain}

Indonesia memiliki banyak filosofi kepemimpinan salah satunya adalah filosofi kempemimpinan dalam adat jawa. Berdasarkan Kosmologi jawa elemen alam digunakan sebagai makna kehidupan dan nilai-nilai kepemimpinan. Nilai-nilai kehidupan disimbolkan berupa angin, air, tanah dan api (gambar 13) yang diartikan sebagai pembentuk dorongan untuk memenuhi kebutuhan jasmani dan rohani. Sifat ini cocok untuk seorang raja/pemimpin (Endraswara 2006).

\section{Konsep Ruang dalam Kosmologi Jawa}

Dalam kosmologi jawa konsep pembagian ruang perlu diperhatikan. Pembagian ruang biasanya menggunakan arah mata angin sebagai acuan. Pada bagian utara merupakan tempat pemerintahan, pada bagian timur merupakan tempat ibadah, pada bagian selatan merupakan bagian pemakaman dan pada bagian barat ialah sebagai tempat perdagangan dan bagian tengah merupakan area tempat berkumpul atau biasa disebut dengan alun-alun. Konsep ruang tersebut terlihat diaplikasikan pada land use Kawasan Medan Merdeka.

Kosmologi jawa mengenal istilah sedulur papat lima pancer yaitu penghormatan pada orang tua, khususnya ibu yang sudah melahirkan kita di muka bumi, dimana disimbolkan kedalam empat elemen yaitu air, tanah, api, angin dan tanah/bumi yang satu dengan yang lainnya saling berkaitan. Keempat unsur tersebut mengikuti arah mata angin yaitu pasaran legi bertempat di Timur. Satu tempat dengan unsur udara, memancarkan aura putih. Pasaran paing bertempat di Selatan salah satu tempat dengan unsur api, selalu memancarkan aura sinar merah. Pasaran pon bertempat di barat karena tempat dengan unsur air, memancarkan sinar kuning. Pasaran wage bertempat di utara, satu tempat dengan unsur tanah, selalu memancarkan sinar hitam. Kelima yaitu kliwon, bertempat di tengah merupakan tempat sukma atau jiwa berada, memancarkan sinar manca warna. Semua unsur tersebut dibaca searah jarum jam. Konsep tersebut diaplikasikan untuk memperkuat karakter pada tapak, yang kemudian dimodifikasi berdasarkan lands use pada tapak

\section{Pengembangan Konsep}

Pengembangan konsep dari konsep dasar untuk memperkuat konsep dasar dan memberikan karakter dan fungsi artwork sebagai mental map bagi kawasannya, konsep dikembangan dalam elemen-elemen pembentuk seperti sirkulasi, vegetasi, warna, visual, suasana

\section{Konsep Sirkulasi}

Konsep sirkulasi menjadi pertimbangan dalam menginterpretasi artwork secara maksimal. Sirkulasi yang digunakan tetap menggunakan sirkulasi eksisting, namun pada titik tertentu user dapat menikmati artwork secara maksimal. Sirkulasi terbagi atas dua yaitu sirkulasi sekunder dan sirkulasi primer (Gambar 15).

\section{Konsep Vegetasi}

Vegetasi sebagai elemen softscape dapat memperkuat karakter terhadap artwork Jenis vegetasi yang digunakan mulai dari groundcover, semak, perdu hingga pohon. Jenis dan warna vegetasi menjadi pertimbangan untuk memperkuat karakter artwork. Konsep vegetasi yang dikembangkan yaitu untuk membentuk karakter visual dan fungsi vegetasi pada lanskap jalan.

\section{Konsep Warna}

Warna yang akan digunakan merupakan warna-warna yang akan mewakili setiap artwork. Warna yang digunakan pada bagian utara adalah warna biru dan ungu untuk menyimbolkan warna air dan memberikan kesan formal, bagian barat menggunakan warna cokelat dan hijau sebagai simbol tanah yang memberikan kesan sejuk, bagian selatan menggunakan warna merah, jingga, dan kuning sebagai simbol api kesan semangat, bagian timur menggunakan warna putih, abu-abu, dan hitam sebagai simbol angin kesan ketenangan. Aplikasi warna digunakan pada material artwork maupun vegetasi (gambar 17).

\section{Konsep Visual}

Visual merupakan salah satu bentuk komunikasi secara tidak langsung. Konsep visual dihadirkan untuk menyampaikan makna/ arti dari artworks terhadap penikmat/ pengguna jalan itu sendiri. Potensi visual yang diciptakan diarahkan ke artwork sehingga pohon-pohon yang tumbuh dirancang membentuk vista sehingga membingkai artworks itu sendiri (gambar 18).

\section{Konsep Suasana}

Suasana dapat memberikan perbedaan karakter satu dengan yang lainnya sehingga sesorang tidak mengalami disorientasi terhadap ruang. Suasana diciptakan untuk memberikan ritme atau irama yang berbeda pada pengguna tapak sehingga mereka mengalami pengalaman yang berbeda-beda. Perbedaan Suasana dimunculkan melalui warna-warna yang dihadirkan diharapkan dapat 
mempengaruhi psikologi pengguna jalan.

\section{Desain}

Desain artwork menggunakan prinsip dan aspek-aspek telah dikemukakan oleh Porteous (1977) dan diaplikasikan kedalam bentukan artwork untuk memberikan karakter dan identitas kawasan sehingga dapat membentuk elemen mental map.

\section{Desain Artwork Jalan Medan Merdeka Utara}

Desain artwork di Medan Merdeka Utara menggunakan transformasi dari bentukan elemen air. Elemen air menggambarkan sifat samudra (laut/air), seluas apapun permukaanya selalu datar dan bersifat sejuk menyegarkan. Hal tersebut menyimbolkan sifat yang harus dimiliki oleh seorang pemimpin yaitu memiliki kasih sayang pada rakyatnya. Menurut Lynch (1960) arti dan makna dapat memberikan image/gambaran yang dapat memperkuat karakter.

Filosofi tersebut ditransformasikan kedalam bentuk artwork. Bentuk dari artwork merupakan transformasi dari proses titisan air untuk memberikan kesan yang dinamis. Artwork diletakkan secara berulang (repetisi) agar pengendara mobil dari arah timur masih dapat menginterpretasi artwork. Pola yang dibentuk didominasi dengan pola organik, untuk memecah kemonotonan tapak, untuk tetap memberikan kesan formal dan luas maka dihadirkan elemen air pada tapak. Visual pada tapak dihadirkan dengan mendominasi warna yang diambil dari warna air yaitu biru. Aplikasi warna diterapkan pada artwork dan vegetasi, ditambah hadirnya elemen air pada tapak.

\section{Desain Artwork Jalan Medan Merdeka Timur}

Desain artwork di Medan Merdeka Timur Menggunakan transformasi dari bentukkan elemen angin. Angin yang berarti selalu ada dimana-mana tanpa membedakan tempat serta selalu mengisi semua ruang yang kosong. Sifat tersebut diartikan bahwa seorang pemimpin selalu dekat dengan rakyat, tanpa membedakan derajat dan martabatnya.

Filosfi angin ditransformasikan kedalam bentuk artwork. Bentuk yang diambil merupakan simbol dari angin yang selalu bergerak. Karakter diperkuat dengan mengambil warna angin yang diaplikasikan pada artwork dan vegetasi.

Desain Artwork Jalan Medan Merdeka Selatan

Desain artwork di Medan Merdeka Selatan menggunakan transformasi dari elemen api. Elemen api dalam hastabrata/sifat kepemimpinan berupa dahana (api), mempunyai kemampuan membakar semua yang bersentuhan dengannya. Seorang pemimpin sebaiknya memiliki semangat, berwibawa dan berani dalam menegakkan kebenaran secara tegas.

Filosofi tersebut diaplikasikan kedalam pola siteplan dan bentuk artwork. Artwork di Medan Merdeka Selatan memiliki dua bentuk yaitu artwork dengan bentuk yang kecil dan yang besar. Artwork yang kecil merupakan transformasi langsung dari elemen api dan diletakkan dari sisi timur menuju sisi barat secara berulang (repetisi) dan pada sisi paling barat dengan artwork yang lebih besar, hal tersebut untuk menggambarkan semangat yang disimbolkan dari api yang menjalar. Selain itu pola siteplan diambil dari bentukan api untuk memberikan kualitas dan meningkatkan sensibilitas, maka didesain jalur pedestrian di dalam tapak agar pejalan kaki dapat menginterpretasi artwork secara lebih dekat. Untuk meningkatkan sensibilitas digunakan warna dari api yaitu merah, kuning, dan oranye. Warna diaplikasikan pada artwork, vegetasi dan pedestrian untuk memperkuat karakter tapak.

\section{Desain Artwork Jalan Medan Merdeka Barat}

Desain artwork di Medan Merdeka Barat menggunakan transformasi bentuk tanah/bumi. Filosofi dari tanah/bumi yaitu bersifat kuat dan murah hati selalu memberi hasil kepada yang merawatnya, begitulah seharusnya seorang pemimpin memiliki sifat bermurah hati (melayani) pada rakyatnya dan tidak mengecewakan rakyatnya. Filosfi tersebut disimbolkan kedalam desain artwork (gambar 19).

Desain artwork Medan Merdeka Barat memiliki dua bagian yaitu yang artwork dengan bentuk stick dengan mounding pada sisi selatan dan stick diletakan secara berulang (repetisi) di sepanjang median jalan. Artwork dengan bentukan stick dangan mounding dibawahnya memiliki arti bahwa tanah (disimbolkan oleh mounding) dapat memberikan penghidupan dan stick tersebut merupakan simbol bagi sebuah kehidupan baru. Artwork dengan stick. Untuk memperkuat karakter digunakan warna alami yaitu cokelat dan hijau dan diaplikasikan pada artwork.

\section{Artwork sebagai Elemen Mental Map}

Untuk menciptakan elemen mental map pada tapak maka artwork didesain dengan memperhatikan aspek-aspek yang dikemukakan oleh Porteous (1977) dan diperkuat dengan teori Lynch (1960) dengan memperhatikan kualitas bentuk yaitu:

\section{Singularity}

Penggunaan bentuk artwork yang berbeda-beda pada masing-masing lokasi dapat menciptakan karakter dan memberikan elemen yang kontras dengan lingkungan sekitarnya sehingga pengamat atau pengguna tapak dapat dengan mudah mengenali lokasi. Aplikasi fungsi singularity pada artwork dapat dilihat pada Gambar 3.

\section{Form Simplicity}




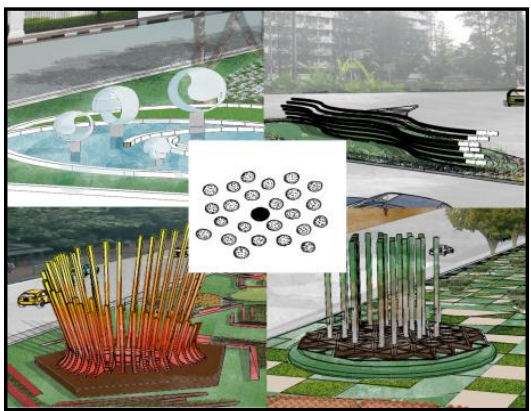

Penggunaan bentuk yang jelas dan sederhana juga dapat mempermudah pengguna jalan dalam mengenali artwork. Penggunaan garis geometrik

\section{Gambar 3. Aplikasifungssingula-} ritypadaartwork

memberikan kesan sederhana dan kuat pada artwork. Selain itu fungsi dari bentuk juga dapat memberikan persepsi terhadap pengguna jalan. Aplikasi dari fungsi form simplicity dapat dilihat pada Gambar 4.

\section{Continuity}

Penggunaan elemen artwork dengan pola yang berulang dan memperhatikan jarak pandang pengguna kendaraan bermotor dan pejalan kaki dapat memberikan visibilitas yang dapat mempengaruhi psikologi pengguna jalan. Karakter continuity dapat memberikan karakter tapak, dengan memperhatikan kualitas tersebut sehingga artwork memiliki fungsi sebagai elemen mental map.

\section{Dominance}

Karakter dominance merupakan bagian yang penting untuk memberikan fungsi elemen mental map, sehingga artwork dapat menjadi elemen utama pada kawasan. Aplikasi fungsi dominance dapat mempengaruhi karakter psikologi pengguna tapak sehingga dapat memberikan image pada kawasan. Karakter dominance diaplikasikan dalam pengulangan bentuk dan penggunaan warna pada material artwork. Directional Differeniation

Perbedaan struktur artwork satu

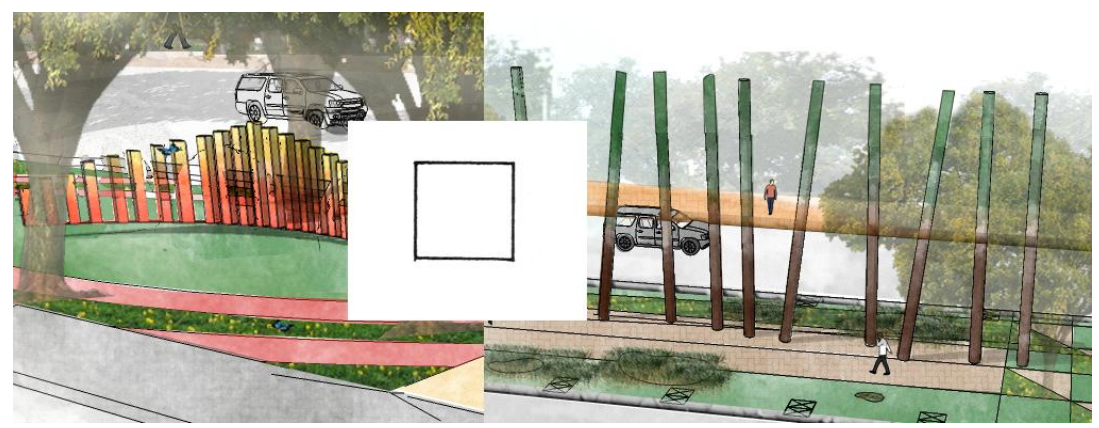

Gambar 4. Aplikasi fungsi form simplicity pada artwork

dengan yang lainnya dapat memberikan perbedaan karakter yang mengarahkan pengguna tapak untuk mengetahui masing-masing lokasi. Kualitas ini dihadirkan dengan memainkan perbedaan skala pada artwork sehingga mempengaruhi psikologi pengguna jalan untuk mudah mengenali lokasi..

\section{Motion Awareness}

Pola pergerakan pengguna jalan dapat memberikan pengalaman dan interpretasi terhadap artwork. Maka didesain jalur pedestrian di dalam tapak agar pejalan kaki dapat menginterpretasi artwork secara lebih dekat (Gambar 5). Karakter motion awareness dihadirkan untuk mengarahkan pengguna jalan dengan adanya artwork sehingga menjadikan artwork tersebut sebagai reference point.

\section{Time Series}

Artwork diletakkan secara berjejer sehingga menghubungkan satu dengan yang lainnya untuk membentuk dan mengarahkan pengguna jalan pada titik klimaks dengan adanya skala artwork yang lebih besar (Gambar 26). Selain itu fungsi time series juga untuk membentuk sequence pada artwork.

\section{SIMPULAN}

Kawasan Medan Merdeka terbagi atas empat lokasi, masing-masing lokasi tersebut memerlukan elemen pembentuk mental map. Artwork sebagai bagian dari elemen lanskap dapat membentuk mental map bagi penggunanya untuk membedakan masing-masing lokasi. Elemen mental map dihadirkan dengan memperhatikan konsep artwork yang dapat menyimbolkan kawasan setempat. Konsep artwork yang diusung yaitu nilai-nilai kepemimpinan dalam kosmologi jawa yang kemudian ditransformasikan ke dalam bentuk elemen alam. Elemen-elemen tersebut berupa air, angin, api dan tanah. Masing-masing elemen tersebut diaplikasikan dalam bentuk artwork dan diaplikasikan pada taman pulau dan median jalan di Jalan Medan Merdeka. Kualitas bentuk menjadi perhatian utama untuk membetuk artwork agar dapat berfungsi sebagai elemen mental map.

\section{Saran}

Dalam perencanaan suatu wilayah atau kawasan baik dalam skala kecil ataupun besar perlu memperhatikan peletakan suatu landmark baik berupa artwork atau beberapa elemen seni/estetika kota untuk memberikan identitas dan karakter pada wilayah atau kawasan tersebut sehingga dapat berfungsi sebagai elemen mental map. Dewasa ini artwork pada kota besar di Jakarta hanya berfungsi sebagai elemen seni tanpa memperhatikan fungsi lainnya seperti fungsi mental map. Sebaiknya pekerja seni dan perencana kota saling bekerjasama dalam menciptakan suatu lanskap yang memiliki karakter dan identitas.
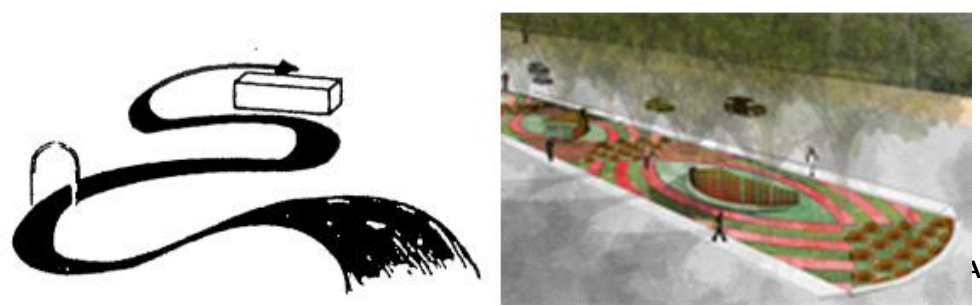

DAFTAR PUSTAKA 
Booth NK.1983. Basic Elements Of Landscape Architectural Design. New York (US): Waveland Press.

[Dir. Bintek] DirektoratBinaTeknik, [ DirjenBinamarga] DirektoratJendra Tata Perkotaandan Tata Pemukiman. 2004. GeometriJalanPerkotaan. Jakarta (ID).

Endraswara S. 2012. Rupadanmaknasimboliknatik motif Modung, Cemukiran.DewaRuci: JurnalPengkajiandanPenciptaanSeni. Vol (8): 107-123 No 1.

Hakim

2004.KomponenPerancanganArsit ekturLansekap. Jakarta (ID): BumiAksara

Hariyanto J. 2004. SitemPengendalianLaluLintasPadaPertemuanJalanSebidang. [Lecture Papers]. Sumatera (ID): USU.

Harris C Dines N. 1998. Time Saver Standards For landscape Architecture: Design and Construction DataSecond Edition. New York (US): McGraw-Hill Publishing Company.
Kartika D S. 2004. SeniRupa Modern. Bandung (ID): RekayasaSains.

[Kemendikbud] KementrianPendidikandanBudaya. 2013. KamusBesarBerbahasa Indonesia Online [Internet] Diaksespada 15 Marret 2013. Tersediadalam http://www.kbbi.com.

Laurie M. 1984. PengantarkepadaArsitekturPertamanan (Terjemahan). Bandung (ID): Intermedia.

Loidl H, Bernard S.2003.Opening Spaces: Design as Landscape Architecture. Birkhauser-publishers for architecture.Berlin(DE): Boston.

Lynch K. 1960. Image of The City. MA (UK): MIT Press.

Lynch K. 1981. A Theory of Good City Form MA (UK): MIT Press.

Marco K. 2004. Jakarta Metropolis TunggangLanggang. Jakarta Pusat (ID): Gagar Media.

Nugraha AAG. 2011. Perancangan Green Wall padaMerketing Office Sentul
City, Bogor. [skripsi]. Bogor(ID): IPB.

Porteous JD. 1977. Environment \& Behavior: Planning and everyday urban life. London (UK): AddisonWesley Longman Publishing Company.

Riiyanto I. 2009.Pemetaan Daerah PotensiBanjirdenganSegmentasi Data Digital Elevation Model.StudiKasus: DAS Ciliwung di DKI Jakarta 2007. [Tesis].Depok (ID): UI.

Simonds JO dan Starke. 2006. Landscpae Architecture: A Manual of Site Planning and design. New York (US): Graw-Hill Book Co.

Simonds JO. 1983. Landscpae Architecture: A Manual of Site Planning and design. New York (US): Graw-Hill Book Co.

Wungkar MM. 2005.EvaluasiAspekFungsidanKu alitasEstetikaArsitekturalPohonLanskapJalan Kota Bogor.[Tesis]. Bogor (ID): IPB. 